\title{
Article \\ A Simple Direct Method to Obtain Kinetic Parameters for Polymer Thermal Decomposition
}

\author{
David Lázaro $^{1, *(\mathbb{D}}$, Alain Alonso ${ }^{1} \mathbb{1}$, Mariano Lázaro ${ }^{1} \mathbb{D}$ and Daniel Alvear ${ }^{2}$ \\ 1 GIDAI Research Group, University of Cantabria, 39005 Santander, Spain; alain.alonso@unican.es (A.A.); \\ mariano.lazaro@unican.es (M.L.) \\ 2 Dirección General de Industria Energía y Minas Gobierno de Cantabria, 39011 Santander, Spain; \\ alvear_md@cantabria.es \\ * Correspondence: lazarod@unican.es
}

check for updates

Citation: Lázaro, D.; Alonso, A.; Lázaro, M.; Alvear, D. A Simple Direct Method to Obtain Kinetic Parameters for Polymer Thermal Decomposition. Appl. Sci. 2021, 11, 11300. https://doi.org/10.3390/ app112311300

Academic Editor: Andrea Dorigato

Received: 4 November 2021

Accepted: 26 November 2021

Published: 29 November 2021

Publisher's Note: MDPI stays neutral with regard to jurisdictional claims in published maps and institutional affiliations.

Copyright: (c) 2021 by the authors. Licensee MDPI, Basel, Switzerland. This article is an open access article distributed under the terms and conditions of the Creative Commons Attribution (CC BY) license (https:// creativecommons.org/licenses/by/ $4.0 /)$.

\begin{abstract}
In a fire, the polymer combustion occurs when gaseous fuels react with oxygen. The heating of a material could force the release of gaseous fuels during thermal decomposition and pyrolysis. The rate of pyrolysis to define the gaseous fuels is usually interpreted by means of the Arrhenius expression and a reaction model expression, which are characterized by an activation energy, a preexponential factor, and a reaction order value. Many methods are available for determining kinetic parameters from thermogravimetric experimental data. However, the most challenging issue is achieving an adequate balance between accuracy and simplicity. This work proposes a direct method for determining the kinetic parameters with only a thermogravimetric experiment at a single heating rate. The method was validated with six polymers, and the results were compared with those from similar procedures, such as the Lyon method and generalized direct method. The results achieved using the simpler approach of the proposed method show a high level of accuracy.
\end{abstract}

Keywords: thermal decomposition; fire chemistry; activation energy; pre-exponential factor; reaction order

\section{Introduction}

The effect of fire or heat and the associated fire hazards of the materials are studied through different phenomena. One of them is the thermal decomposition, which occurs when chemical compounds are heated. These thermal decomposition reactions are defined by the amount of gaseous fuel released, the release rate, and the temperature of each reaction. This phenomenon is fundamental to understand and simulate fire and its propagation between different elements. Therefore, a pyrolysis sub-model is a fundamental part of fire computational models [1].

Thermal analysis comprises a group of experimental techniques that measure changes in physical, mechanical, and chemical properties during controlled heating [2,3]. The thermal decomposition characteristics of a solid may be determined by the kinetic analysis of the data [4-6]. Rates are parameterized in terms of temperature, pressure, and the degree of conversion, $\alpha$, which is defined as:

$$
\alpha=\frac{m_{0}-m}{m_{0}-m_{f}}
$$

where $m_{0}$ is the initial mass, $m_{f}$ is the final mass, and $m$ is the mass at a given time. $\alpha$ is a dimensionless parameter. The influence of pressure is frequently ignored in kinetic studies, and most kinetic methods consider the rate to be a function only of temperature and the degree of conversion [7]. The rate constant, $k(T)$, describes the velocity of the reaction as a function of temperature, and the reaction model, $f(\alpha)$, describes the dependence on $\alpha$. The rate of thermal decomposition, $d \alpha / d t$, is expressed as 


$$
\frac{d \alpha}{d t}=k(T) \cdot f(\alpha)
$$

Although there are other approaches for representing $k(T)$ [8], the Arrhenius expression, given by Equation (3)-where $A$ is the pre-exponential factor $\left(\mathrm{s}^{-1}\right), E\left(\mathrm{~J} \mathrm{~mol}^{-1}\right)$ is the activation energy [2], $R$ is the gas constant $\left(\mathrm{J} \mathrm{mol}^{-1} \mathrm{~K}^{-1}\right)$, and $T$ is the temperature (K)-is commonly used to describe the temperature dependence of a rate process [9].

$$
k(T)=A \cdot e^{\left(-\frac{E}{R \cdot T}\right)}
$$

Although $A$ and $E$ are attributed to the frequency of molecular collisions and to the energy barrier of chemical bond breaking, respectively, as a mechanistic interpretation by some authors, these quantities may be considered to be adjustable parameters of $k(T)$ [10].

The influence of $\alpha$ on the rate process may be expressed in terms of accelerating, decelerating, or sigmoidal models. We focus on the decelerating model in this paper, because this formalism is commonly applied to thermal decomposition reactions in fire science [1,2]. The decelerating model applies to processes where the rate initially exhibits its maximum value and decreases continuously as the degree of conversion increases. The most widely applied description of this process is the following reaction-order expression, which depends on $\alpha$ and the reaction order, $n$ (dimensionless parameter):

$$
f(\alpha)=(1-\alpha)^{n}
$$

The kinetic parameters, $E, A$, and $n$, provide the ability to generate predictive thermal curves which can be used to assess the rate of thermal decompositions in terms of percent conversion, time, and temperature. These thermal decompositions can be of different nature, as melting crystallization, pyrolysis, oxidative reactions, etc. There are several methods for obtaining the kinetic parameters to describe the thermal decomposition of polymers [5,11-26]. However, each method has particular constraints and limitations and may require some factors to be ignored to simplify interpretation [2].

The two approaches developed to study the kinetic parameters of thermal decomposition can be categorized as analytical and curve-fitting optimization methods [2] (see Figure 1). These are further divided into model-fitting and model-free methods. In model-fitting methods, the kinetic parameters are defined in terms of previously established reaction mechanisms. The direct differential [12], Freeman-Carroll [13], and Coats-Redfern [14] approaches are the most commonly used of these methods. These methods consider the activation energy and pre-exponential factor to be constant throughout the entire reaction. However, some practitioners [12] limit $\alpha$ to an experimental range between 0.01 and 0.11 at the low limit and between 0.67 and 0.98 at the high limit, depending on the material, reaction order, and method. This is completed because extreme curvature is observed in experiments at large $\alpha$, which leads to deviation from Arrhenius behavior, especially for the direct differential method.

There are isoconversional and non-isoconversional methods of analysis. Isoconversional methods evaluate the kinetic parameters at successive values of $\alpha$ rather than applying a reaction model [10]. These methods typically require kinetic curves at different heating rates because they assume that the activation energy is the same at each degree of conversion. However, some studies show large differences in the thermal decomposition of certain materials at different heating rates $[3,15]$. The most popular isoconversional approaches are the standard isoconversional [16], Ozawa-Flynn-Wall [17], Friedman [18], Vyazovkin [19], and Kissinger-Akahira-Sunose [20] methods. These methods are controversial according to the study [21] that claim that the activation energy obtained using integral isoconversional methods is mathematically incorrect and recommend avoiding them. 


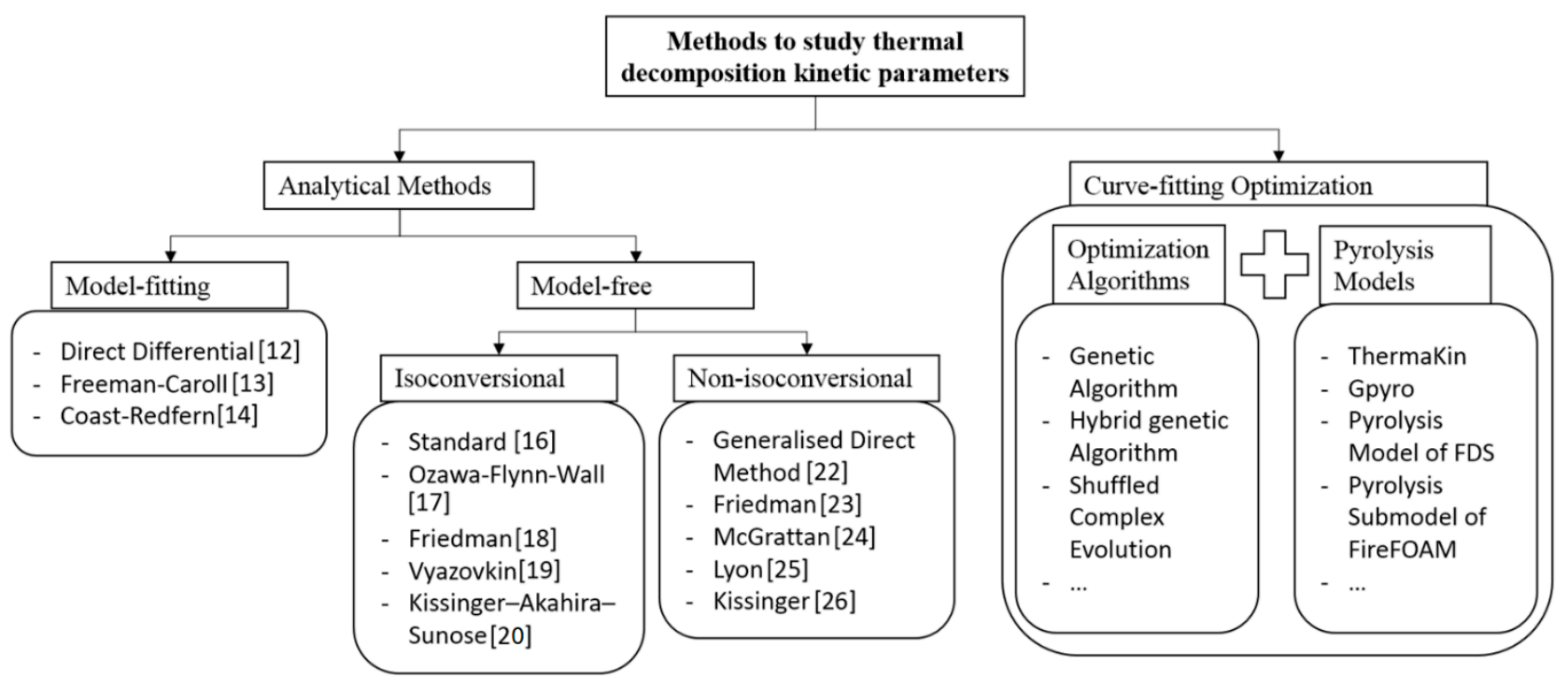

Figure 1. Methods developed to calculate kinetic decomposition parameters (adapted from [2]).

Model-free non-isoconversional methods allow direct calculation of the activation energy and pre-exponential factors using a single equation. These methods are generally easy to apply, but can be sensitive to data noise [22]. The most commonly used examples are the generalized direct (GDM) [22], Friedman [23], McGrattan [24], Lyon [25], and Kissinger [26] methods. The differences among these methods lie in the definition of the reference point used to obtain the kinetic parameters. The reference point in the Lyon method is chosen at the maximum decomposition rate, whereas the GDM considers the reference point to be the position where the third derivative of the decomposition rate is zero. The dependence on the definition of a single point requires a separate analysis to be conducted for each method.

Finally, curve-fitting optimization methods are very efficient for complex processes involving multiple reactions, but require significant computational effort [27-36].

In summary, isoconversional model-free methods require kinetic curves at different heating rates. However, the definition of kinetic parameters as a function of the degree of conversion does not allow their direct use in computational pyrolysis models. Nonisoconversional model-free methods can be directly applied to computational models because it is necessary to have only a single kinetic curve at a certain heating rate. However, these methods employ a unique reference point in defining the reaction and are, therefore, very sensitive to competing reactions [9]; these equations do not necessarily follow a perfect exponential Arrhenius response. Curve-fitting optimization methods are more precise, because they require only an individual kinetic curve at a certain heating rate and can be directly applied to computational models. However, their complexity makes their utilization difficult for non-experts. Therefore, the challenge is to develop a method with a suitable balance between accuracy and complexity.

A modification of the direct differential method [12] is proposed to address this issue. This approach allows simple analytical equations to be used for calculating the kinetic parameters of thermal decomposition while assigning equal weight to the decomposition behavior at the beginning, middle, and end of the process. Kinetic parameters calculated via the proposed method are evaluated by comparison to the results obtained by the established protocols of the Lyon $[25,37]$ and GDM $[22,38]$ methods, which are widely used for obtaining kinetic parameters for pyrolysis models used in numerical fire simulations [1]. The Lyon and GDM methods are chosen, because they use simple analytical equations to calculate a single activation energy and pre-exponential factor for each decomposition reaction and are applicable to a single thermogravimetric result. 
The remainder of the paper is divided into sections as follows. Section 2 contains a description of the proposed method. Section 3 describes the polymers examined and experimental procedures. Section 4 presents the results obtained by application of the proposed method and shows a comparison of these with results from the Lyon and GDM methods. The results are discussed in Section 5.

\section{Approach for a New Direct Method}

Our approach uses a model-fitting method based on a direct differential method $[2,12]$ using the Arrhenius equation and a reaction-order model to define the kinetic process. This proposed method (PM) enables users to obtain kinetic parameters by resolution of a few simple equations that can be easily automated. The combination of Equations (2)-(4) yields:

or

$$
\frac{d \alpha}{d t}=A \cdot e^{\left(-\frac{E}{R \cdot T}\right)} \cdot(1-\alpha)^{n}
$$

$$
\frac{d \alpha}{d t} \cdot \frac{1}{(1-\alpha)^{n}}=A \cdot e^{\left(-\frac{E}{R \cdot T}\right)}
$$

Equation (6) can be expressed as Equation (7) using Napierian logarithms,

$$
\ln \frac{\frac{d \alpha}{d t}}{(1-\alpha)^{n}}=\ln A-\left(\frac{E}{R \cdot T}\right)
$$

where the logarithmic argument on the left-hand side of the equation is represented by:

$$
F^{\prime}(\alpha)=\frac{\frac{d \alpha}{d t}}{(1-\alpha)^{n}}
$$

As $n, A, E$, and $R$ are considered constant during a particular decomposition reaction, the Equation (7) is a linear equation expressed in terms of the variables $\ln F^{\prime}(\alpha)$ (y-coordinates) and $1 / T$ (x-coordinates). The activation energy is obtained from its slope, $s$, by use of Equation (9):

$$
s=-\frac{E}{R}
$$

The slope is calculated by dividing the difference between the y-coordinates of two points by the difference between the $\mathrm{x}$-coordinates of the same two points:

$$
s_{\alpha_{1}-\alpha_{2}}=\frac{\ln F^{\prime}\left(\alpha_{1}\right)-\ln F^{\prime}\left(\alpha_{2}\right)}{\frac{1}{T_{\alpha_{1}}}-\frac{1}{T_{\alpha_{2}}}}
$$

where $s_{\alpha_{1}-\alpha_{2}}$ is the slope between $\alpha_{1}$ and $\alpha_{2}$. However, it is necessary to determine the reaction order, $n$, to do so. We use the equation of Friedman [23], which considers the three points $\alpha_{a}, \alpha_{b}$, and $\alpha_{c}$ shown in Figure 2. These points are located in three distinct regions along the path of conversion so that the same weight is assigned to kinetic parameters calculated in the initial $\left(\alpha_{1}\right.$ to $\left.\alpha_{2}\right)$, middle $\left(\alpha_{3}\right.$ to $\left.\alpha_{4}\right)$, and final $\left(\alpha_{5}\right.$ to $\left.\alpha_{6}\right)$ stages of thermal decomposition. The reaction order is calculated by means of Equation (11):

$$
n=\frac{\ln \left(\frac{\frac{d \alpha_{c}}{d T}}{\frac{d \alpha_{a}}{d T}}\right)-\frac{T_{b} \cdot\left(T_{c}-T_{a}\right)}{T_{c} \cdot\left(T_{b}-T_{a}\right)} \cdot \ln \left(\frac{\frac{d \alpha_{b}}{d T}}{\frac{d \alpha_{a}}{d T}}\right)}{\frac{T_{b} \cdot\left(T_{c}-T_{a}\right)}{T_{c} \cdot\left(T_{b}-T_{a}\right)} \cdot \ln \left(\frac{1-\alpha_{a}}{1-\alpha_{b}}\right)-\ln \left(\frac{1-\alpha_{a}}{1-\alpha_{c}}\right)}
$$




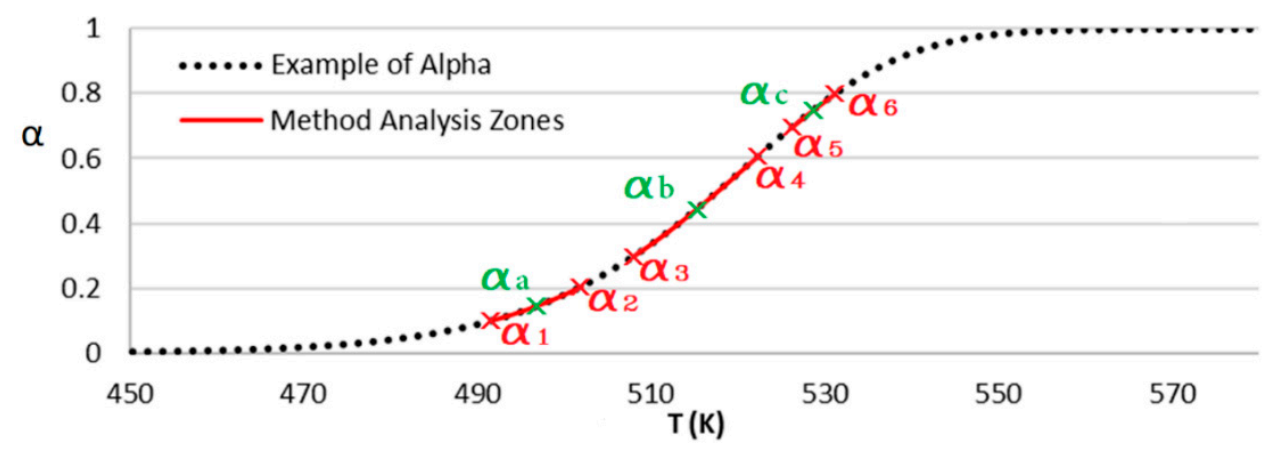

Figure 2. Location of $\alpha$ intervals for reaction order determination.

To evaluate this equation, we need to derivate the experimental $\alpha$ versus the temperature. Then, by considering $\alpha_{a}, \alpha_{b}$, and $\alpha_{c}$ equals to $0.15,0.45$, and 0.65 , respectively, we can calculate the associated $d \alpha / d T$ and $T$ to obtain $n$ from Equation (11). Once $n$ is calculated, $F^{\prime}(\alpha)$ can be evaluated with the desired experimental values of $\alpha$ and $d \alpha / d t$, and the calculated $n$.

The slope is determined from data corresponding to three intervals in the course of reaction. The points $\alpha_{1}$ through $\alpha_{6}$ are defined at $0.1,0.2,0.3,0.6,0.7$, and 0.8 , respectively, and the activation energy is calculated by Equation (12):

$$
E=-\left(\frac{\frac{\ln F^{\prime}\left(\alpha_{1}\right)-\ln F^{\prime}\left(\alpha_{2}\right)}{\frac{1}{T_{\alpha_{1}}}-\frac{1}{T_{\alpha_{2}}}}+\frac{\ln F^{\prime}\left(\alpha_{3}\right)-\ln F^{\prime}\left(\alpha_{4}\right)}{\frac{1}{T_{\alpha_{3}}}-\frac{1}{T_{\alpha_{4}}}}+\frac{\ln F^{\prime}\left(\alpha_{5}\right)-\ln F^{\prime}\left(\alpha_{6}\right)}{\frac{1}{T_{\alpha_{5}}}-\frac{1}{T_{\alpha_{6}}}}}{3}\right) \cdot R
$$

Following the determination of $E$ and $n$, the pre-exponential factor is estimated using Equation (13), which follows from Equation (7) by considering the values of $\alpha_{1}$ to $\alpha_{6}$ and the average values of $1 / T_{\alpha i}$ and $\ln F\left(\alpha_{i}\right)$, where $i=1-6$ and $n_{\alpha}=6$ are the numbers of $\alpha$ evaluated.

$$
A=e^{\frac{\sum_{i=1}^{n_{\alpha}}\left(\frac{E_{a}}{R} \cdot \frac{1}{T_{\alpha_{i}}}+\ln F\left(\alpha_{i}\right)\right)}{n_{\alpha}}}
$$

The methodology was applied to multiple decomposition reactions by segmenting the mass results. This may be done automatically considering the second derivative of the mass loss or by the visual association of each peak of the mass versus temperature derivative $(d m / d T)$ curve with a reaction. The latter procedure was chosen for the cases analyzed in this study for the PVC, but the first one is described below for the poly(methaphenylene isophthalamide) (NOMEX) as it undergoes thermal decomposition in several overlapping steps.

\section{Application to Decomposition Reactions for Overlapping Steps}

The application of the methodology to multiple decomposition reactions requires the segmentation of the TG results. This requirement implies the definition of the different decomposition reactions pertaining to the polymer by directly analyzing the TG and $d m / d T$ experimental curves by the user or by an automatized method to define the different reactions.

One way to automatize the definition of the decomposition reactions is to associate each peak of the $d m / d T$ curve with a reaction. In the $d m / d T$, the local maximum defines the points of the different reactions when more mass is released, and the local minimum is the separation between the different reactions. It is necessary to remark that this method separates decomposition by the predominant reaction in each temperature range considering decomposition reactions as consecutives.

According to this, the second derivative of the mass loss $\left(d \mathrm{~m}^{2} / d T^{2}\right)$ helps to directly obtain $d m / d T$ maximum and minimum when $d m^{2} / d T^{2}$ is equal to 0 . This can be used to define material reactions, as shown in the Figures 3 and 4 for the NOMEX. In Figure 3, we 
can see two different peaks in the NOMEX $d m / d T$. The first peak is associated with the first reaction and the second peak with the second reaction, respectively. In Figure 3, we can appreciate that the separation between both reactions is produced at the same temperature of the zero value of $d m^{2} / d T^{2}$ (vertical grey line). Figure 4 shows the representation of the two considered reactions in the TG curve.

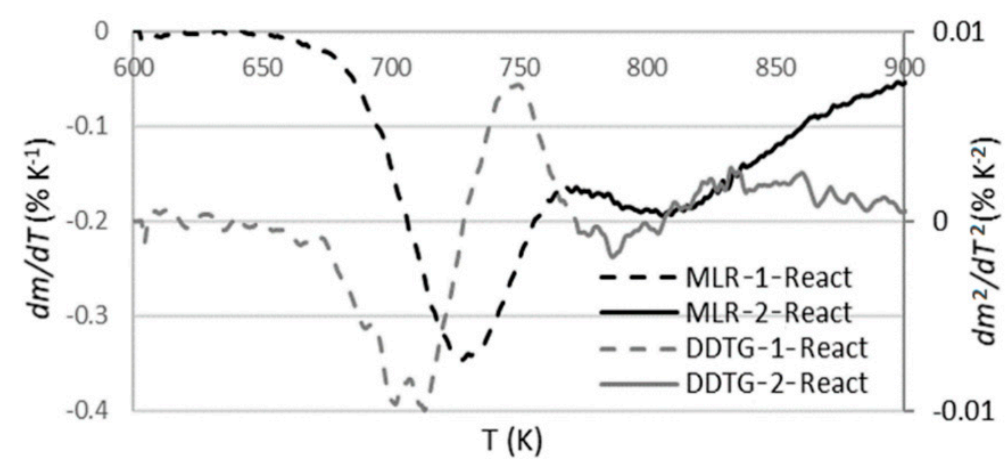

Figure 3. Second derivative method to define the decomposition reactions applied to NOMEX. $d m / d T$ black line and $d m^{2} / d T^{2}$ grey line.

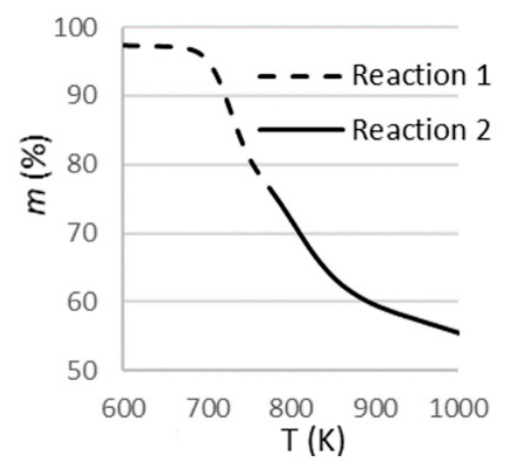

Figure 4. Reactions in the NOMEX mass defined by the second derivative method.

Once the different reactions considered are defined, the proposed methodology is applied independently to each one of them. To do so, the degree of conversion, $\alpha$, is calculated for each reaction using Equation (1), as shown in Figure 5.

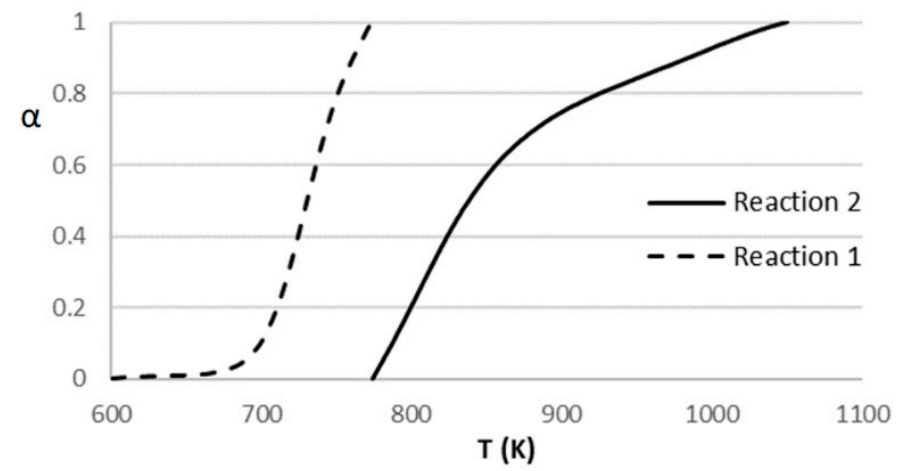

Figure 5. Degree of conversion vs. T for each defined reaction.

\section{Materials and Experimental Setup}

The polymers selected for study were poly(hexamethylene adipamide) (PA 6.6 or nylon 6.6), acrylonitrile/butadiene/styrene copolymer (ABS), poly(vinyl chloride) (PVC), linear low-density poly(ethylene) (LLDPE), poly(methyl methacrylate) (PMMA), and poly(methaphenylene isophthalamide) (NOMEX). 
PA 6.6 was analyzed at heating rates of $2.5,5,10,20$, and $40 \mathrm{~K} \mathrm{~min}^{-1}$. Although heating rate of $40 \mathrm{~K} \mathrm{~min}^{-1}$ is high enough to not be recommended by the ICTAC, it is included in the validation analysis as it is allowed by the standard [39] and higher values of heating rate are used by several authors for specific applications [33,34]. The other polymers were studied at a single heating rate of $10 \mathrm{~K} \mathrm{~min}^{-1}$ (Table 1) to examine decomposition patterns.

Table 1. Materials tested and heating rates.

\begin{tabular}{cc}
\hline Material & Heating Rate $\left(\mathbf{K ~ m i n}^{-\mathbf{1}}\right)$ \\
\hline PA 6.6 & $2.5,5.0,10.0,20.0,40.0$ \\
ABS, PVC, LLDPE, PMMA, NOMEX & 10.0 \\
\hline
\end{tabular}

A Netzsch STA 449 F3 instrument was used to carry out thermogravimetric experiments. The apparatus can operate at temperatures between 303 and $1773 \mathrm{~K}$ in oxidative or inert atmospheres. Its temperature and mass resolutions were $0.001 \mathrm{~K}$ and $0.1 \mu \mathrm{g}$, respectively. Because we are concerned with pyrolysis, all measurements were conducted under an inert atmosphere with a nitrogen gas flow of $40 \mathrm{~mL} \mathrm{~min}{ }^{-1}$. The percentage mass losses and $d m / d T$ responses for the six materials at a heating rate of $10 \mathrm{~K} \mathrm{~min}^{-1}$ for the temperature range where decomposition processes also took place, as shown in Figure 6a,b.

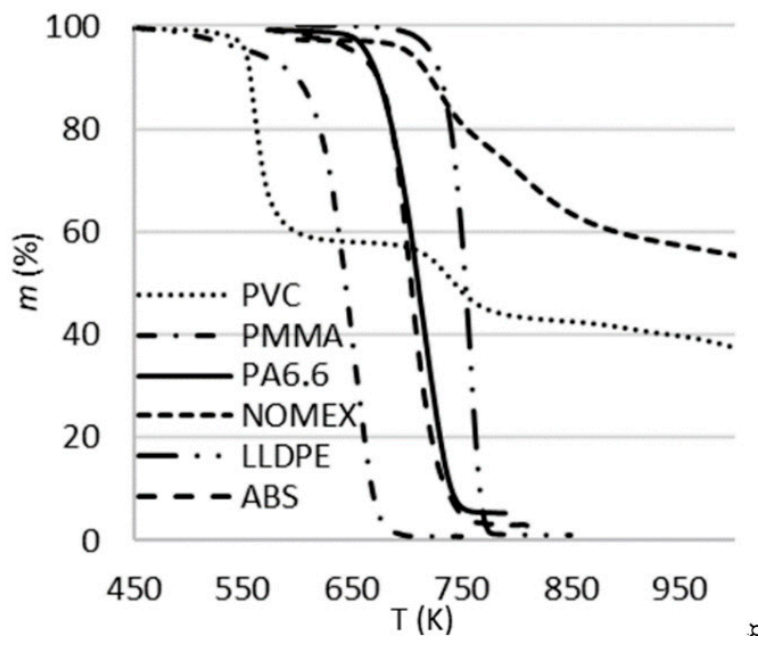

(a)

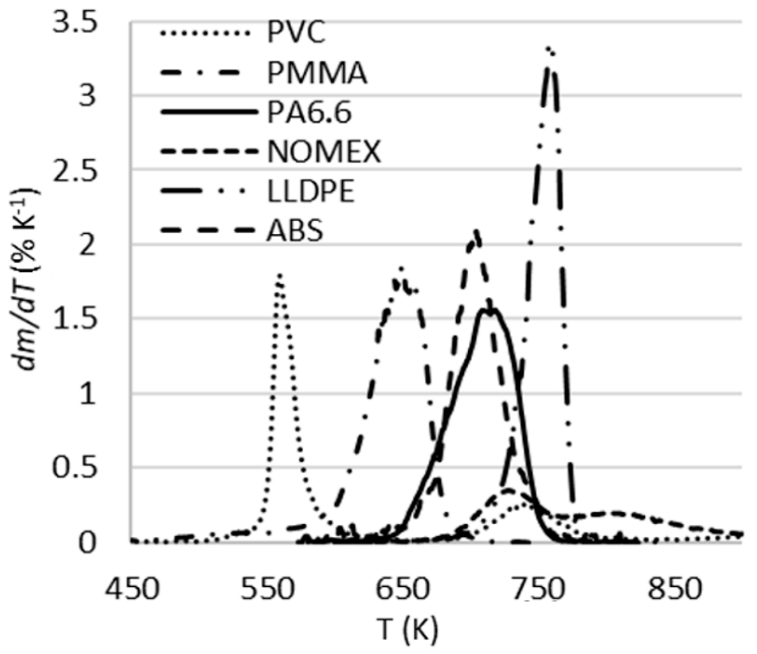

(b)

Figure 6. Experimental (a) TG and (b) $d m / d T$ responses of six polymer materials examined at a heating rate of $10 \mathrm{~K} \mathrm{~min}{ }^{-1}$.

The results indicate that the thermal decomposition processes exhibit different patterns of behavior depending on the material in question. PA 6.6, LLDPE, and ABS undergo a single abrupt decomposition reaction, PMMA and NOMEX participate in a lengthier combined process, and PVC undergoes distinct stepwise reactions.

\section{Results}

The methodology is applied to calculate the kinetic parameters for the PA 6.6 at heating rates of $2.5,5,10,20$, and $40 \mathrm{~K} \mathrm{~min}^{-1}$, and for the other polymers at one single heating rate of $10 \mathrm{~K} \mathrm{~min}^{-1}$. For each case, the obtained kinetic parameters for the different methodologies are compared. These kinetic parameters are used to calculate the mass and $d m / d T$ curves which are compared with the experimental ones. Furthermore, we calculate the mean absolute error of the experimental mass and $d m / d T$ curves with those obtained by the kinetic methods. The mean absolute error is the average over the test, considering a temperature step of $1 \mathrm{~K}$, of the absolute differences between prediction and experimental results where all individual differences have equal weight. Finally, we also compare the maximum $d m / d T$ values and their temperatures. 
Table 2 summarizes the kinetic parameters obtained for PA 6.6 at different heating rates. The three kinetic parameters obtained by the proposed method are compared with those obtained by the Lyon and GDM methods.

Table 2. Comparison of kinetic parameters for the decomposition reaction of PA6.6.

\begin{tabular}{|c|c|c|c|c|c|c|c|c|c|}
\hline \multirow{2}{*}{$\begin{array}{l}\text { Heating Rate } \\
\quad\left(\mathrm{K}_{\left.\text {min }^{-1}\right)}\right.\end{array}$} & \multicolumn{3}{|c|}{ Proposed Method } & \multicolumn{3}{|c|}{ Lyon Method } & \multicolumn{3}{|c|}{ GDM } \\
\hline & $\begin{array}{c}E \\
\left(\mathrm{~kJ} \mathrm{~mol}^{-1}\right)\end{array}$ & $A\left(s^{-1}\right)$ & $\mathbf{n}$ & $\begin{array}{c}\mathrm{E} \\
\left(\mathrm{kJ} \mathrm{mol}^{-1}\right)\end{array}$ & $A\left(s^{-1}\right)$ & $\mathbf{n}$ & $\begin{array}{c}\mathrm{E} \\
\left(\mathrm{kJ} \mathrm{mol}{ }^{-1}\right)\end{array}$ & $A\left(s^{-1}\right)$ & $\mathbf{n}$ \\
\hline 2.5 & 192 & $1.27 \times 10^{12}$ & 1.5 & 140 & $1.03 \times 10^{8}$ & 1 & 189 & $4.80 \times 10^{11}$ & 0.84 \\
\hline 5 & 175 & $5.05 \times 10^{10}$ & 1.16 & 170 & $2.25 \times 10^{10}$ & 1 & 195 & $1.45 \times 10^{12}$ & 0.87 \\
\hline 10 & 181 & $1.25 \times 10^{11}$ & 0.96 & 187 & $5.14 \times 10^{11}$ & 1 & 202 & $4.07 \times 10^{12}$ & 0.77 \\
\hline 20 & 160 & $3.15 \times 10^{9}$ & 0.72 & 204 & $5.59 \times 10^{12}$ & 1 & 234 & $8.14 \times 10^{14}$ & 0.82 \\
\hline 40 & 184 & $2.36 \times 10^{11}$ & 0.84 & 212 & $2.57 \times 10^{13}$ & 1 & 233 & $6.90 \times 10^{14}$ & 1.04 \\
\hline
\end{tabular}

A graphical comparison of the kinetic parameters is shown in Figure 7. The proposed method has the narrowest range of activation energy and pre-exponential factor values. These quantities range from $\mathrm{E}=160$ to $192 \mathrm{~kJ} \mathrm{~mol}^{-1}$ and $\mathrm{A}=3.15 \times 10^{9}$ to $1.27 \times 10^{12} \mathrm{~s}^{-1}$. The reaction order calculated by the proposed method decreases from 1.5 to 0.72 at heating rates from 2.5 to $20 \mathrm{~K} \mathrm{~min}^{-1}$, but increases to 0.84 at $40 \mathrm{~K} \mathrm{~min}^{-1}$.

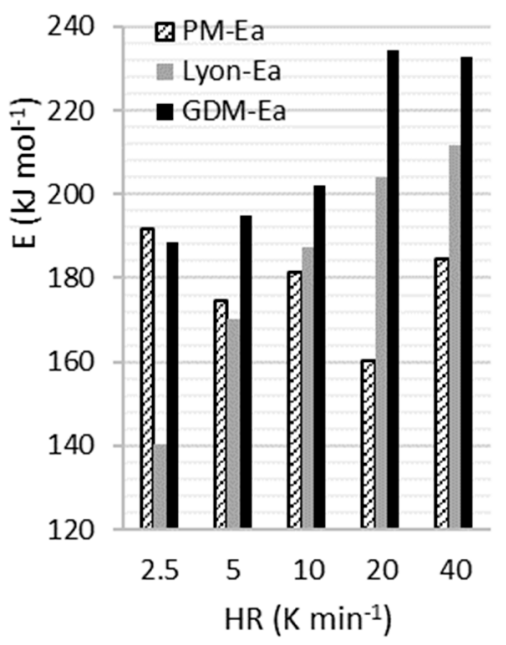

(a)

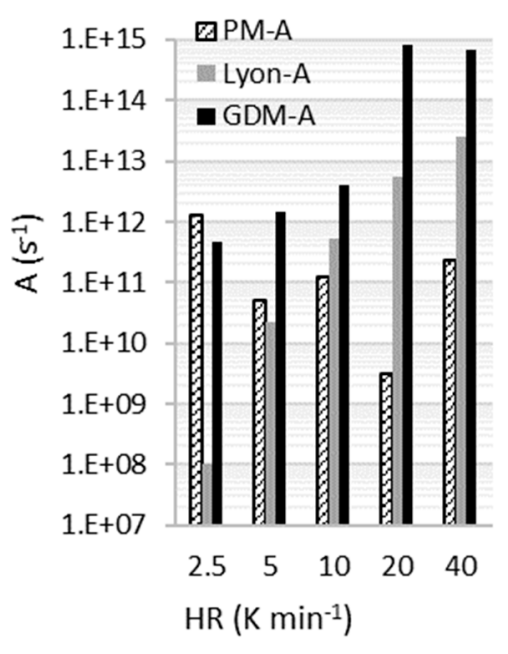

(b)

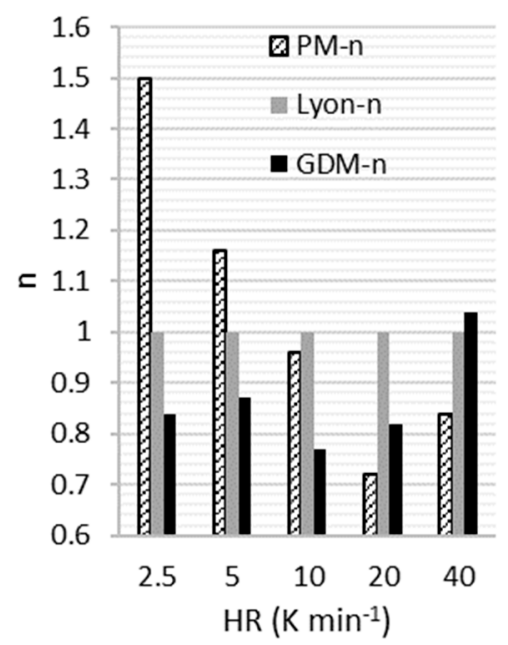

(c)

Figure 7. A comparison of (a) activation energy, (b) pre-exponential factor, and (c) the reaction order of PA 6.6 decomposition as a function of heating rate by different kinetic methods.

We prepared mass versus $T$ and $d m / d T$ versus $T$ curves to determine the accuracy of these estimates. By solving the differential equation (Equation (4)) using each set of kinetic parameters, values of $\alpha$ as a function of temperature may be obtained by calculating the sample mass as a function of temperature using the expression:

$$
m=m_{0}-\alpha \cdot\left(m_{0}-m_{\text {res }}\right)
$$

where $m_{0}$ and $m_{\text {res }}$ are the initial and residual masses, respectively. The mass percentage is obtained by dividing the instantaneous mass by the initial mass and multiplying by 100 . The $d m / d T$ response is calculated by taking the derivative of the mass versus temperature behavior. The mass- $T$ and $d m / d T-T$ responses were plotted for the Lyon, GDM, and proposed methods, and were used to compare absolute errors in the determination of mass values and $d m / d T$ peak positions. 
Table 3 shows a comparison of the mean absolute error of the experimental mass- $T$ and $d m / d T-T$ curves with those obtained by the other kinetic methods. The errors equal the average of the absolute value differences between the calculated and experimental results at each temperature. All three methods provide a good correlation of the thermal decomposition behavior of PA 6.6 at all heating rates. The Lyon method produces the best results at $20 \mathrm{~K} \mathrm{~min}^{-1}$ (Figure 8), whereas the proposed method provides the best results at 2.5, 5 (Figure 9), 10, and $40 \mathrm{~K} \mathrm{~min}^{-1}$. The absolute average error using the proposed method is less than $1.628 \%$ for mass measurements and less than $0.045 \% \mathrm{~K}^{-1}$ for $d m / d T$ measurements over all heating rates.

Table 3. Mean absolute error in experimental versus calculated mass- $T$ and $d m / d T-T$ results for PA 6.6.

\begin{tabular}{ccccccc}
\hline \multirow{2}{*}{ Curve } & Method & \multicolumn{5}{c}{ HR $\left(\mathbf{K} \mathbf{~ m i n}^{-\mathbf{1}}\right)$} \\
\cline { 3 - 7 } & & $\mathbf{2 . 5}$ & $\mathbf{5}$ & $\mathbf{1 0}$ & $\mathbf{2 0}$ & $\mathbf{4 0}$ \\
\hline \multirow{3}{*}{ Mass (\%) } & PM & 0.488 & 0.694 & 0.611 & 1.628 & 1.070 \\
& Lyon & 2.660 & 1.342 & 3.367 & 0.576 & 1.076 \\
& GDM & 1.964 & 1.275 & 1.004 & 1.484 & 0.987 \\
\hline \multirow{3}{*}{$d m / d T\left(\% \mathrm{~K}^{-1}\right)$} & PM & 0.038 & 0.030 & 0.024 & 0.045 & 0.034 \\
& Lyon & 0.052 & 0.039 & 0.108 & 0.035 & 0.036 \\
& GDM & 0.128 & 0.085 & 0.079 & 0.094 & 0.053 \\
\hline
\end{tabular}

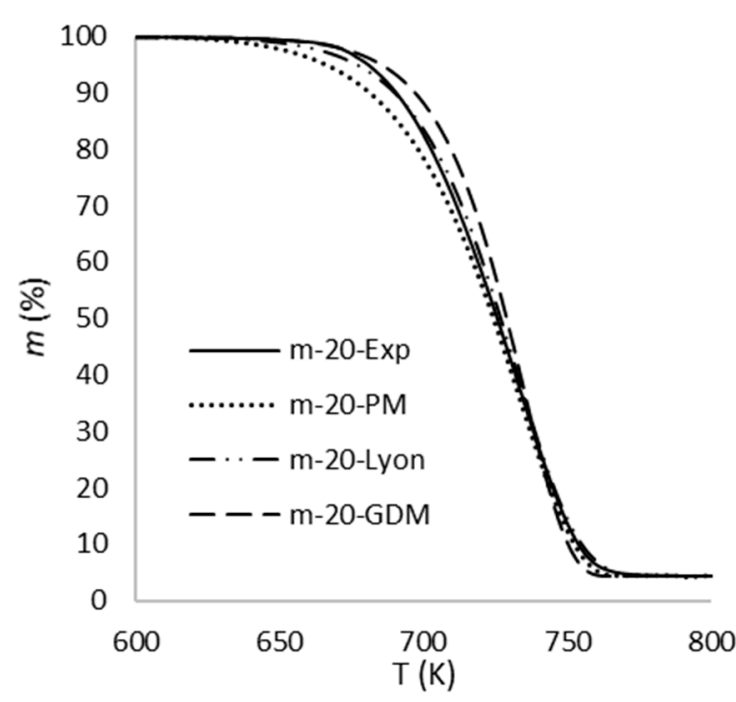

(a)

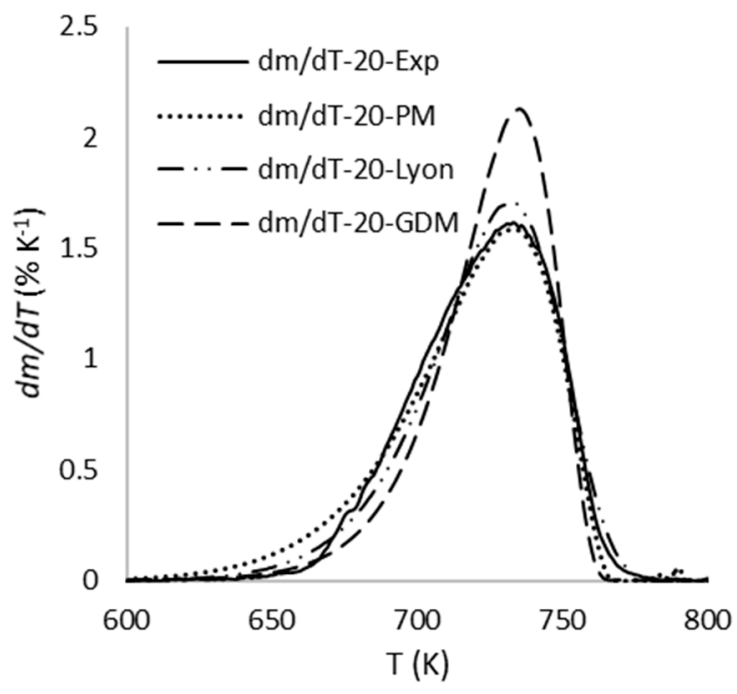

(b)

Figure 8. A comparison of experimental and calculated (a) mass and (b) $d m / d T$ results for PA 6.6 at a heating rate of $20 \mathrm{~K} \mathrm{~min}^{-1}$. 


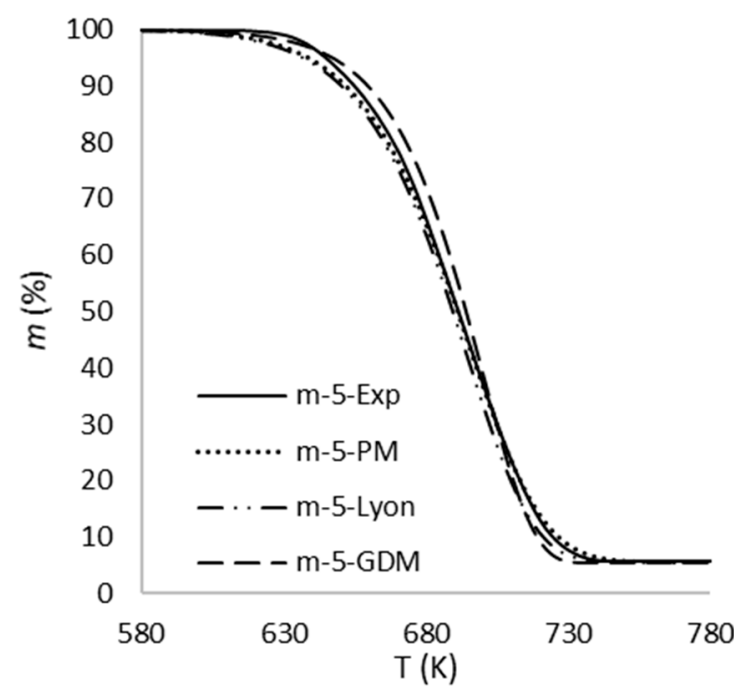

(a)

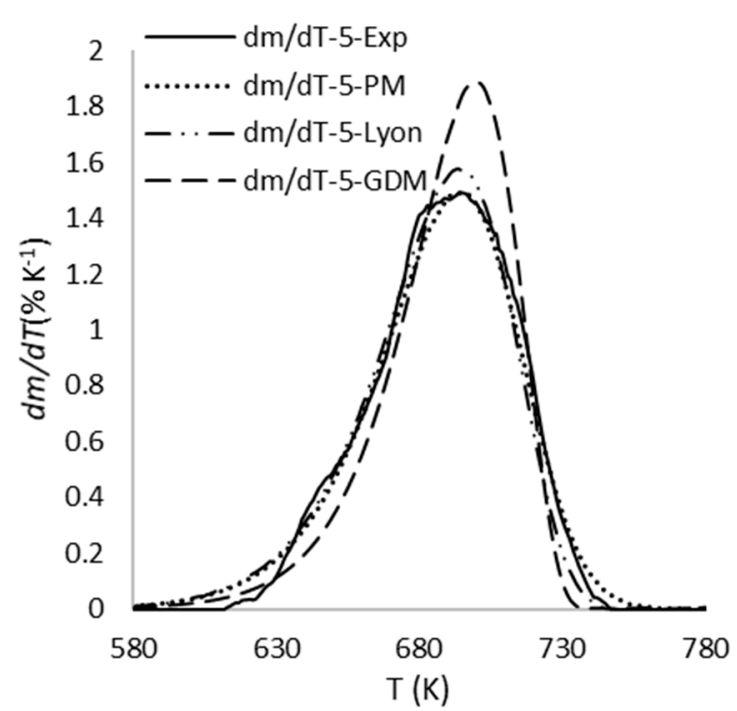

(b)

Figure 9. A comparison of experimental and calculated (a) mass and (b) $d m / d T$ results for PA 6.6 at a heating rate of $5 \mathrm{~K} \mathrm{~min}^{-1}$.

Table 4 summarizes the maximum $d m / d T$ values and temperatures. The calculated results closely match the experimental ones, particularly for the proposed method.

Table 4. Comparison of $d m / d T$ maximum values and temperatures for PA 6.6.

\begin{tabular}{|c|c|c|c|c|c|}
\hline & & Experiment. & PM & Lyon & GDM \\
\hline \multirow{2}{*}{ HR_2.5K $\mathrm{min}^{-1}$} & $d m / d T \max \left(\% \mathrm{~K}^{-1}\right)$ & 1.37 & 1.48 & 1.37 & 1.91 \\
\hline & Temp. $d m / d T \max (\mathrm{K})$ & 676 & 676 & 677 & 686 \\
\hline \multirow{2}{*}{ HR_5K $\min ^{-1}$} & $d m / d T \max \left(\% \mathrm{~K}^{-1}\right)$ & 1.49 & 1.49 & 1.58 & 1.89 \\
\hline & Temp. dm/dT $\max (\mathrm{K})$ & 695 & 696 & 694 & 700 \\
\hline \multirow{2}{*}{ HR_10K $\min ^{-1}$} & $d m / d T \max \left(\% \mathrm{~K}^{-1}\right)$ & 1.57 & 1.61 & 1.67 & 1.97 \\
\hline & Temp. $d m / d T \max (\mathrm{K})$ & 718 & 715 & 708 & 717 \\
\hline \multirow{2}{*}{$\mathrm{HR} \_20 \mathrm{~K} \min ^{-1}$} & $d m / d T \max \left(\% \mathrm{~K}^{-1}\right)$ & 1.62 & 1.58 & 1.71 & 2.13 \\
\hline & Temp. $d m / d T \max (\mathrm{K})$ & 733 & 731 & 733 & 735 \\
\hline \multirow{2}{*}{$\mathrm{HR} \_40 \mathrm{~K} \mathrm{~min}^{-1}$} & $d m / d T \max \left(\% \mathrm{~K}^{-1}\right)$ & 1.67 & 1.65 & 1.74 & 1.84 \\
\hline & Temp. $d m / d T \max (\mathrm{K})$ & 741 & 743 & 740 & 744 \\
\hline
\end{tabular}

Evaluation of the methods for studying polymer degradation was further tested by examining the decomposition patterns of the other five materials at a heating rate of $10 \mathrm{~K} \mathrm{~min}^{-1}$. NOMEX undergoes thermal decomposition in several overlapping steps (Figure 6). PVC degrades in two distinct reactions, whereby hydrogen chloride gas is evolved nearly quantitatively by a chain-stripping mechanism (dehydrochlorination) between 500 and $650 \mathrm{~K}$, and the second reaction $(700-800 \mathrm{~K}$ ) corresponds to the pyrolysis of the polyene sequences formed during the previous reaction [15]. PMMA, ABS, and LLDPE decompose via a single thermal reaction.

Table 5 shows kinetic parameters obtained with the different methodologies for all polymers. The reaction order was set at 1 for the first step of PVC decomposition in the proposed and GDM methods, as this value is fixed in the Lyon method. This was done because Equation (11) did not yield a realistic value of $n$, and a minimum error value could not be established within the range of $n$ obtained. The problem, which deserves further study, may be related to the reaction model used to describe the decomposition reactions. 
Table 5. Comparison of kinetic decomposition parameters for five materials at a heating rate of $10 \mathrm{~K} \mathrm{~min}^{-1}$.

\begin{tabular}{|c|c|c|c|c|c|c|c|c|c|c|}
\hline \multirow{2}{*}{\multicolumn{2}{|c|}{ Material }} & \multicolumn{3}{|c|}{ Proposed Method } & \multicolumn{3}{|c|}{ Lyon Method } & \multicolumn{3}{|c|}{ GDM } \\
\hline & & $\begin{array}{c}E \\
\left(\mathrm{~kJ} \mathrm{~mol}^{-1}\right)\end{array}$ & $A\left(s^{-1}\right)$ & $\mathbf{n}$ & $\begin{array}{c}E \\
\left(\mathrm{KJ} \mathrm{mol}^{-1}\right)\end{array}$ & $A\left(s^{-1}\right)$ & $\mathbf{n}$ & $\begin{array}{c}E \\
\left(\mathrm{~kJ} \mathrm{~mol}^{-1}\right)\end{array}$ & $A\left(s^{-1}\right)$ & $\mathbf{n}$ \\
\hline \multicolumn{2}{|c|}{ ABS } & 347 & $7.52 \times 10^{23}$ & 2.01 & 241 & $7.98 \times 10^{15}$ & 1 & 248 & $1.96 \times 10^{16}$ & 1.76 \\
\hline \multicolumn{2}{|c|}{ LLDPE } & 352 & $2.05 \times 10^{22}$ & 0.76 & 444 & $4.82 \times 10^{28}$ & 1 & 440 & $3.12 \times 10^{28}$ & 0.96 \\
\hline \multicolumn{2}{|c|}{ PMMA } & 188 & $9.19 \times 10^{12}$ & 0.92 & 289 & $2.66 \times 10^{21}$ & 1 & 197 & $5.28 \times 10^{13}$ & 1.06 \\
\hline \multirow[b]{2}{*}{ NOMEX } & R1 & 275 & $4.15 \times 10^{17}$ & 1.76 & 184 & $1.04 \times 10^{11}$ & 1 & 314 & $1.71 \times 10^{20}$ & 1.76 \\
\hline & $\mathrm{R} 2$ & 125 & $3.38 \times 10^{5}$ & 2.73 & 125 & $4.73 \times 10^{5}$ & 1 & 126 & $2.93 \times 10^{5}$ & 4.96 \\
\hline \multirow{2}{*}{ PVC } & R1 & 197 & $1.62 \times 10^{16}$ & 1 & 301 & $2.80 \times 10^{26}$ & 1 & 314 & $2.33 \times 10^{27}$ & 1 \\
\hline & $\mathrm{R} 2$ & 295 & $7.97 \times 10^{18}$ & 2.45 & 97 & $2.29 \times 10^{4}$ & 1 & 280 & $4.19 \times 10^{17}$ & 1.19 \\
\hline
\end{tabular}

Similar values for the activation energies of ABS and LLDPE using the proposed method can be seen. Nevertheless, the higher pre-exponential factor of ABS (36 times higher than the one of LLDPE) makes the decomposition reaction occur at lower temperatures. The reaction order was 2.01 for ABS and 0.76 for LLDPE. The higher reaction order of the ABS makes the end of the decomposition reaction slower than the LLDPE one. Comparing the ABS and PMMA kinetic parameters, it can be seen that, although the pre-exponential factor of PMMA is lower than the ABS one, by decreasing the reaction rate according to Equation (5), the lower activation energy of PMMA increases more the reaction rate (Equation (5)), leading to the decomposition reaction at lower temperatures for the PMMA. The proposed and GDM methods yielded similar values of $\mathrm{E}=188$ and $197 \mathrm{~kJ} \mathrm{~mol}^{-1}$ and $\mathrm{A}=9.19 \times 10^{12}$ and $5.28 \times 10^{13} \mathrm{~s}^{-1}$, respectively, for PMMA, and $\mathrm{E}=295$ and $280 \mathrm{~kJ} \mathrm{~mol}^{-1}$ and $\mathrm{A}=7.97 \times 10^{18}$ and $4.19 \times 10^{17} \mathrm{~s}^{-1}$, respectively, for the second reaction of PVC. The kinetic parameter differences between the proposed and the GDM and Lyon methods are greater for the other polymers. A valid value of $n$ cannot be established for multi-step reactions, as in the case of NOMEX. Thus, $n$ is selected to provide the smallest error. The partially overlapping character of the NOMEX reactions also necessitates the smoothing of calculated mass results. Graphical comparisons of the kinetic parameters obtained by the proposed, Lyon, and GDM methods are shown in Figure 10.

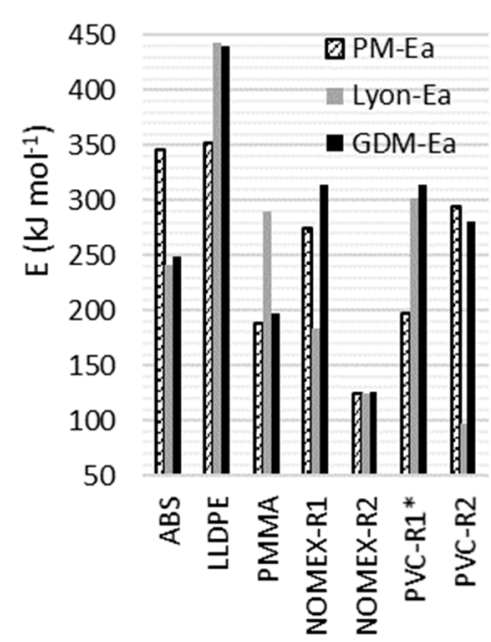

(a)

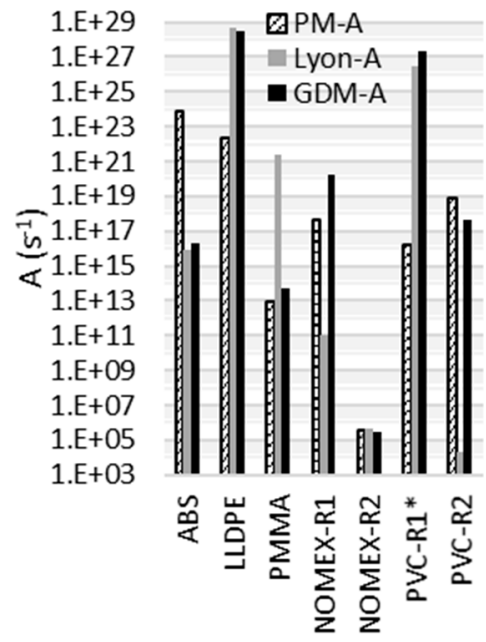

(b)

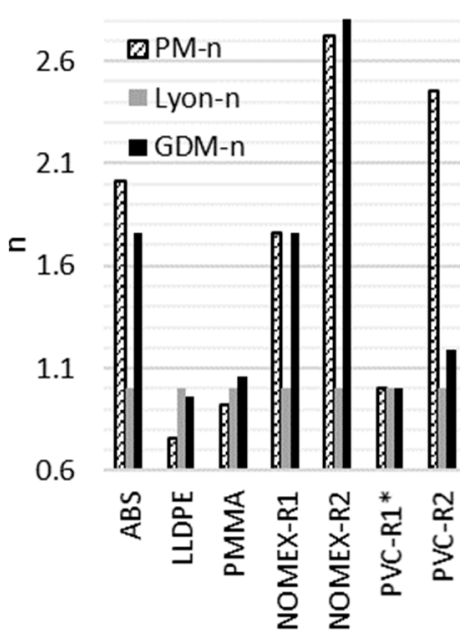

(c)

Figure 10. A comparison of the (a) activation energies, (b) pre-exponential factors, and (c) reaction orders of polymer materials at $10 \mathrm{~K} \mathrm{~min}^{-1}$ obtained by different kinetic methods. 
Table 6 lists the mean absolute error of the mass- $T$ and $d m / d T-T$ responses at $10 \mathrm{~K} \mathrm{~min}^{-1}$. The largest TGA error obtained by the proposed method is $2.507 \%$ for PMMA. The largest $d m / d T$ error is $0.084 \% \mathrm{~K}^{-1}$ for PVC. The proposed method yields the smallest mean absolute error in all cases except for the $d m / d T$ result of PVC.

Table 6. Mean absolute error of mass- $T$ and $d m / d T-T$ responses versus experimental results for five polymer materials obtained by different methodologies.

\begin{tabular}{ccccccc}
\hline Curve & Method & ABS & LLDPE & PMMA & NOMEX & PVC \\
\hline \multirow{3}{*}{ Mass } & PM & 1.234 & 0.303 & 2.507 & 0.613 & 0.982 \\
& Lyon & 3.030 & 1.688 & 3.640 & 3.475 & 2.357 \\
& GDM & 2.404 & 0.725 & 2.700 & 2.663 & 1.190 \\
\hline \multirow{3}{*}{$d m / d T$} & PM & 0.044 & 0.027 & 0.050 & 0.010 & 0.084 \\
& Lyon & 0.115 & 0.077 & 0.147 & 0.037 & 0.116 \\
& GDM & 0.104 & 0.034 & 0.051 & 0.032 & 0.070 \\
\hline
\end{tabular}

Table 7 shows a comparison of the calculated values of the $d m / d T$ maximum and its temperature with experimental results for five polymer materials. The proposed method provides a good approximation of the experimental values in all cases.

Table 7. Comparison of $d m / d T$ maximum values and temperature with experimental results for five polymer materials.

\begin{tabular}{cccccc}
\hline \multirow{2}{*}{ ABS } & & Experiment. & PM & Lyon & GDM \\
& $d m / d T \max \left(\% \mathrm{~K}^{-1}\right)$ & 2.11 & 2.11 & 2.20 & 1.63 \\
& Temp. $d m / d T \max (\mathrm{K})$ & 704 & 704 & 704 & 709 \\
\hline \multirow{2}{*}{ LLDPE } & $d m / d T \max \left(\% \mathrm{~K}^{-1}\right)$ & 3.36 & 3.16 & 3.45 & 3.51 \\
& Temp. $d m / d T \max (\mathrm{K})$ & 758 & 759 & 760 & 758 \\
\hline \multirow{2}{*}{ PMMA } & $d m / d T \max \left(\% \mathrm{~K}^{-1}\right)$ & 1.84 & 2.13 & 3.12 & 2.08 \\
& Temp. $d m / d T \max (\mathrm{K})$ & 649 & 653 & 649 & 652 \\
\hline \multirow{2}{*}{ NOMEX-R1 } & $d m / d T \max \left(\% \mathrm{~K}^{-1}\right)$ & 0.35 & 0.38 & 0.34 & 0.41 \\
& Temp. $d m / d T \max (\mathrm{K})$ & 728 & 732 & 729 & 740 \\
\hline \multirow{2}{*}{ NOMEX-R2 } & $d m / d T \max \left(\% \mathrm{~K}^{-1}\right)$ & 0.20 & 0.20 & 0.27 & 0.09 \\
& Temp. $d m / d T \max (\mathrm{K})$ & 805 & 786 & 805 & 804 \\
\hline \multirow{2}{*}{ PVC-R1 } & $d m / d T \max \left(\% \mathrm{~K}^{-1}\right)$ & 1.81 & 1.17 & 1.82 & 1.86 \\
& Temp. $d m / d T \max (\mathrm{K})$ & 559 & 565 & 559 & 564 \\
\hline \multirow{2}{*}{ PVC-R2 } & $d m / d T \max \left(\% \mathrm{~K}^{-1}\right)$ & 0.26 & 0.23 & 0.14 & 0.33 \\
& Temp. $d m / d T \max (\mathrm{K})$ & 746 & 735 & 745 & 747 \\
\hline
\end{tabular}

Figures 11-15 provide comparisons of the predicted and experimental TGA and $d m / d T$ results using the proposed, Lyon, and GDM methods.

The GDM method provides the best fit to the ABS response at temperatures below $690 \mathrm{~K}$. However, the proposed method fits the mass and $d m / d T$ results better than the other methods from this point until the end of the reaction. The proposed method provides the best fit to the experimental mass loss results of LLDPE throughout the reaction. 


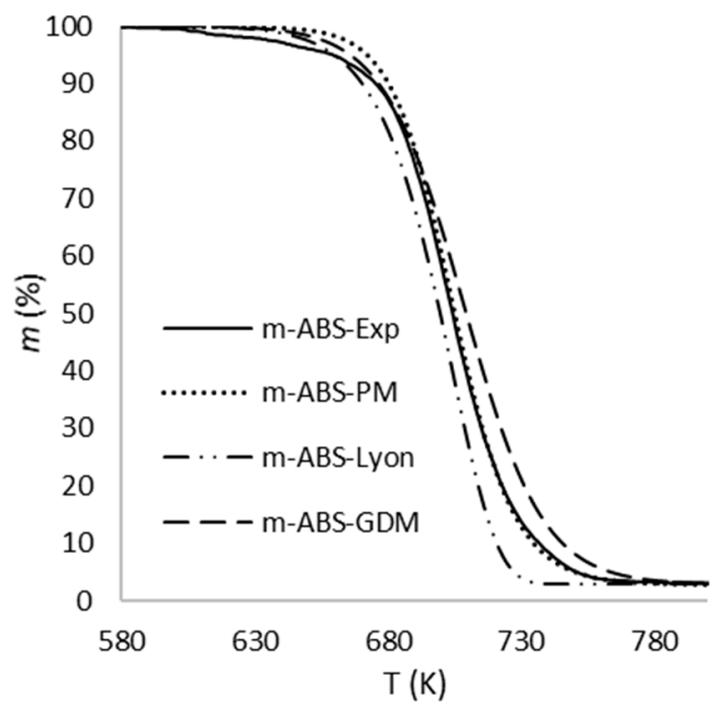

(a)

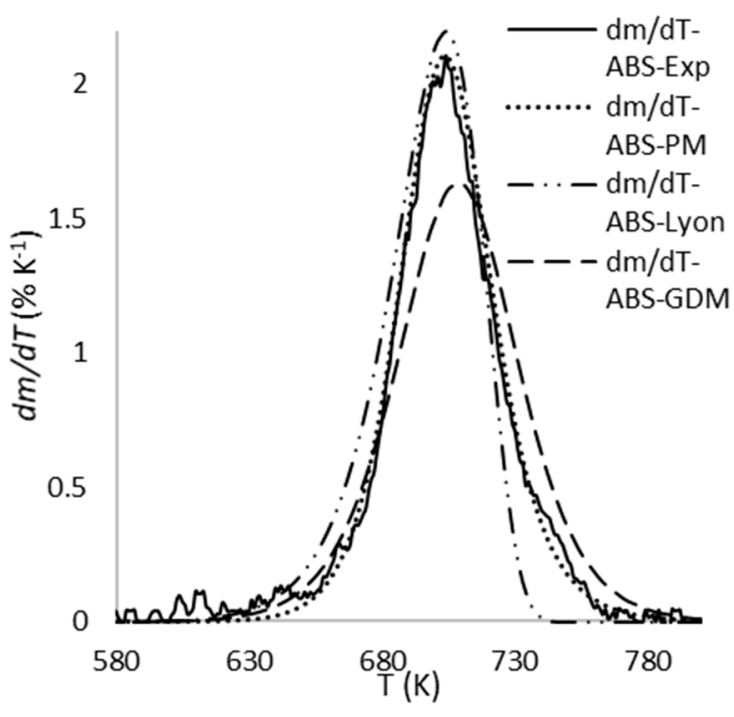

(b)

Figure 11. A comparison of experimental and calculated (a) mass and (b) $d m / d T$ results for ABS.

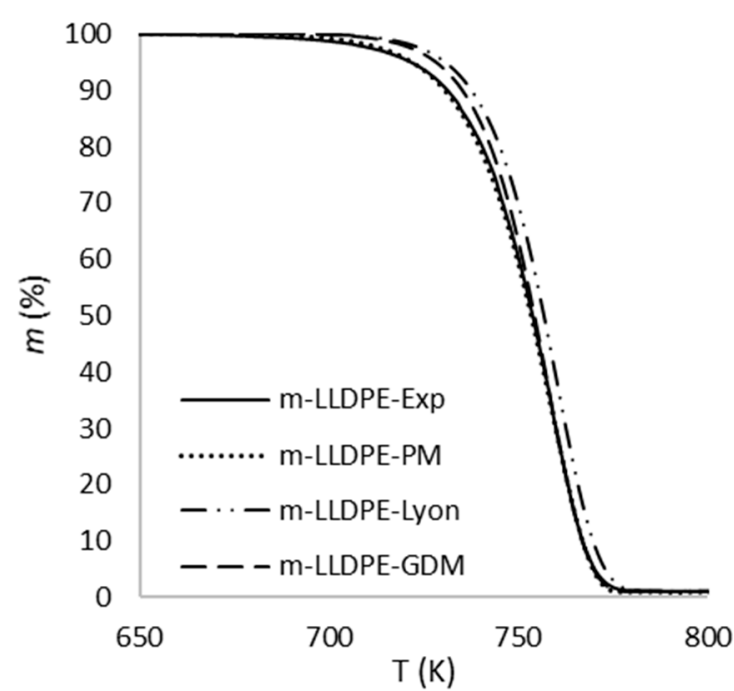

(a)

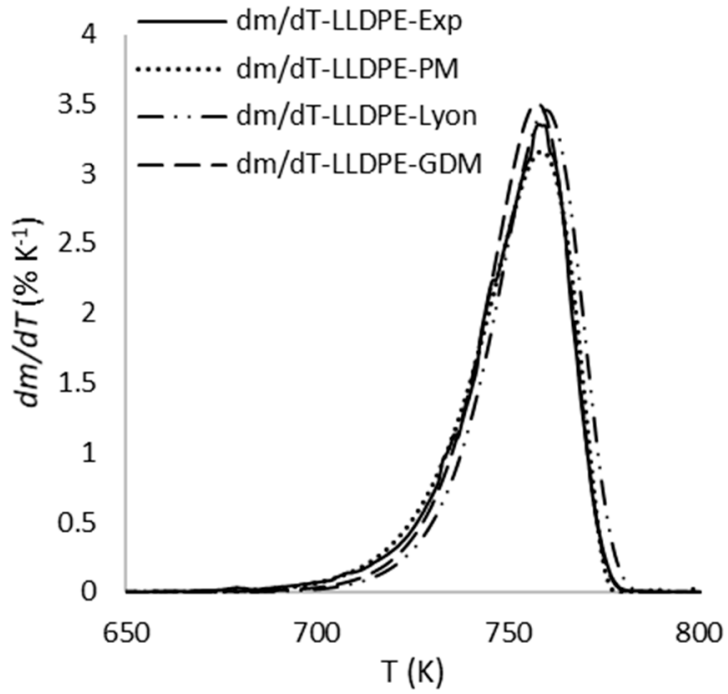

(b)

Figure 12. A comparison of experimental and calculated (a) mass and (b) $d m / d T$ results for LLDPE.

None of the methods predict the initial mass decrease shown in the mass data for PMMA. However, the proposed and GDM methods correctly predict the overall weight loss. Figure $13 \mathrm{~b}$ shows that the temperature of the $d m / d T$ maximum is accurately predicted by all methods.

The proposed method best approximates the experimental NOMEX results by considering the process as two reactions. Although all methods are able to approximately define the first reaction, only the proposed method obtains a more accurate approximation to the second reaction. 


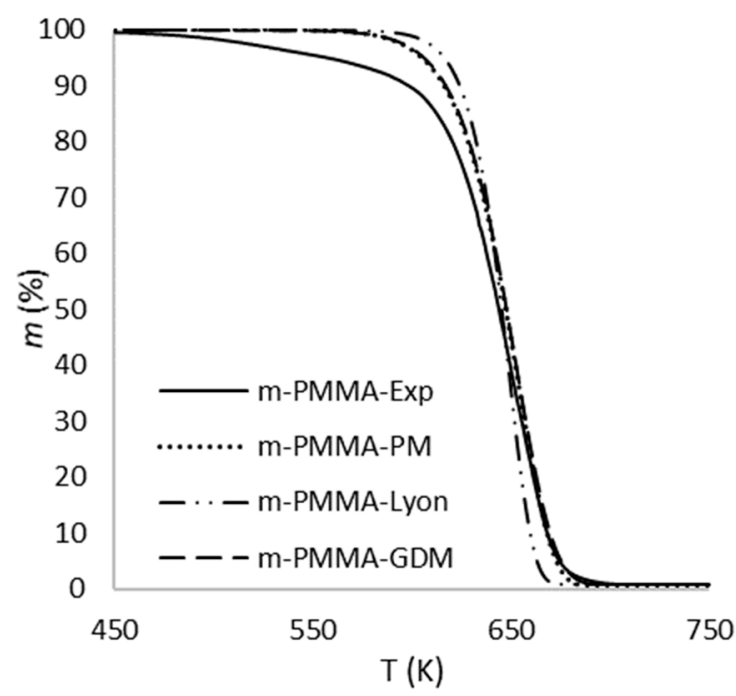

(a)

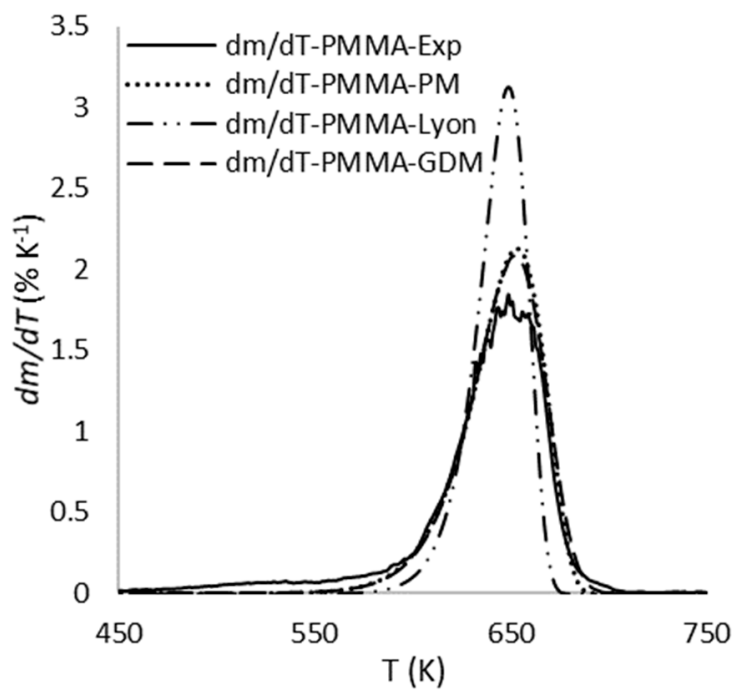

(b)

Figure 13. A comparison of experimental and calculated (a) mass and (b) $d m / d T$ results for PMMA.

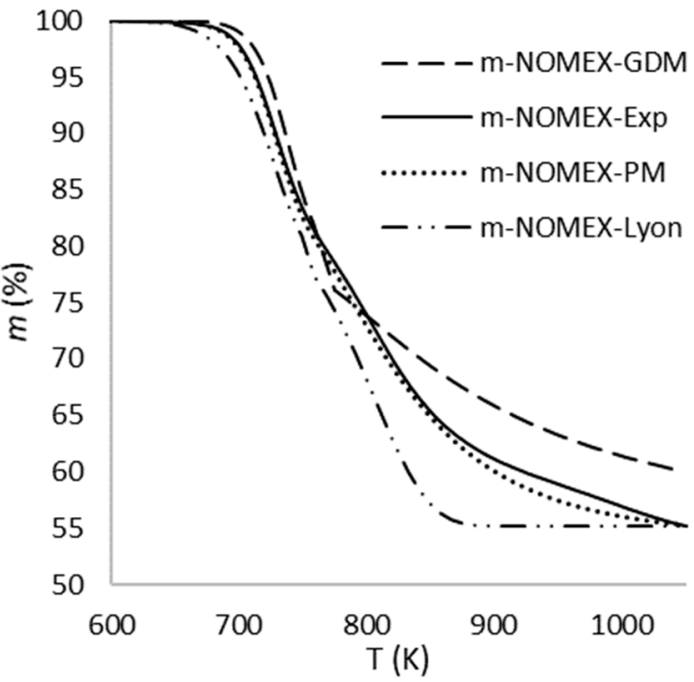

(a)

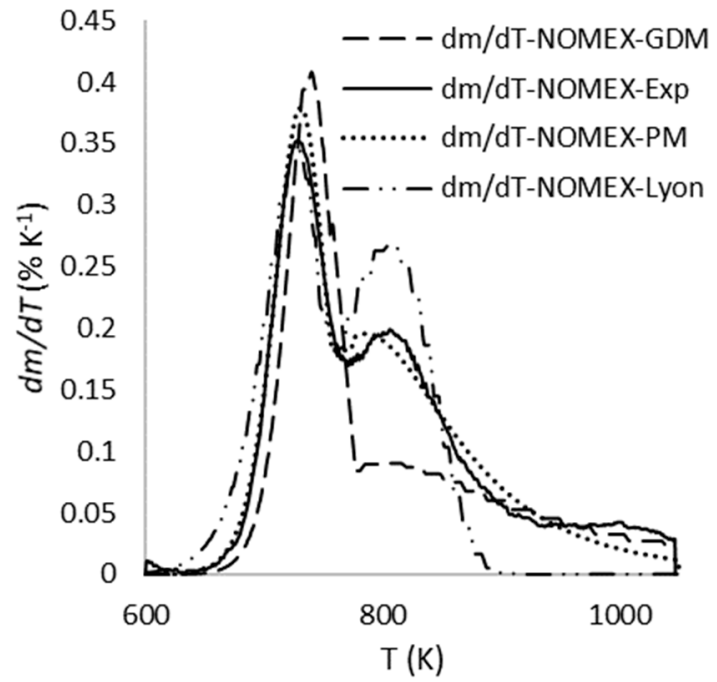

(b)

Figure 14. A comparison of experimental and calculated (a) mass and (b) $d m / d T$ results for NOMEX.

All three methods provide an acceptable, but not perfect, description of the first PVC reaction (dehydrochlorination). The proposed method produces the best fit to the second reaction based on the mass and $d m / d T$ results. 


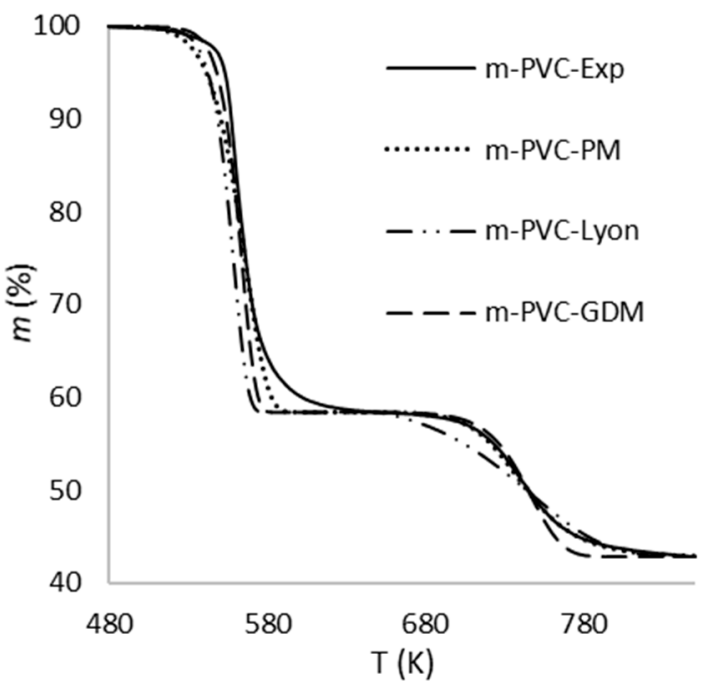

(a)

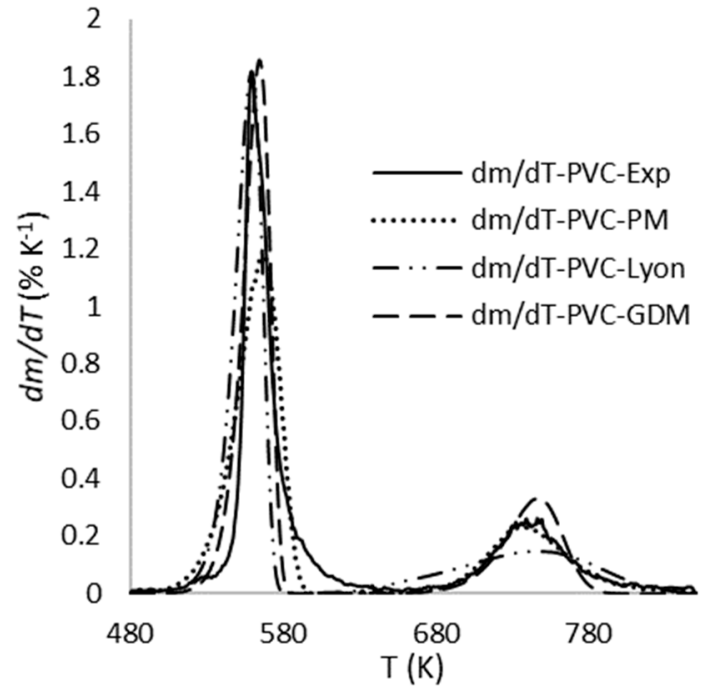

(b)

Figure 15. A comparison of experimental and calculated (a) mass and (b) $d m / d T$ for PVC.

\section{Discussion}

Although the Arrhenius equation adjusts as much as possible to experimental results, it only approximates the thermal decomposition behavior, which can be perturbed by experimental noise and competing reactions. These limitations make it unlikely that perfect results will be obtained.

It is useful also to highlight some considerations regarding application of the Lyon and GDM methods. The former is valid only for a reaction first order. The latter is employed using different equations [22] to calculate the reaction order and maximum and minimum of the second $\alpha$ derivative and to choose the kinetic parameters that best fit the experimental curve.

In estimating the kinetic parameters at different heating rates, there is a tendency for the activation energy and pre-exponential factor predicted by the Lyon method to vary, which occurs because these quantities are determined using only the $d m / d T$ maximum as a single reference point. As the $d m / d T$ maximum moves to higher temperatures with increasing heating rate, the activation energy increases. The GDM produces considerable variation in the estimated kinetic parameters without exhibiting the trend of the Lyon method. The variability results from the methodology of the GDM approach, which prioritizes obtaining a good representation of the experimental response rather than the homogeneity of the equations used.

The proposed method overcomes these constraints by considering three regions of the curve (beginning, middle, and end) to estimate kinetic parameters characteristic of the entire reaction. The use of several reference points along the course of the reaction may explain why the proposed method does not produce the trend in activation energy and pre-exponential values exhibited by the Lyon method. The new method also produces the narrowest range of $\mathrm{E}$ and $\mathrm{A}$ values at all heating rates and a smaller dependence on reaction order. Nevertheless, variation in the kinetic parameters with heating rate is still observed. The variability could arise from the influence of heating rate on the nature of the decomposition reactions, where it has been shown $[3,15]$ that the boundary conditions (including heating rate) employed in the definition of the TGA response can change the temperature at which reactions take place and the kind of material produced upon decomposition.

Although GDM and Lyon methods can be applied to analyze complex behavior, such as that exhibited by NOMEX, where decomposition occurs by competitive reactions. When it is applied to competitive reactions with more than one step, it is not possible to define a unique and separate peak in the second derivative to calculate kinetic parameters. This 
seems to affect the results of these methods, producing worse results when competitive rather than consecutive reactions occur.

The proposed method is applicable to single, consecutive, and partially competitive reactions, as illustrated by the results shown in Table 6, which show the lowest error under all conditions except for the $d m / d T$ result of PVC. Special attention should be paid to the analysis of competitive reactions. The new method can be applied to other reaction models by modifying Equation (7) to fit specific circumstances better, such as the first decomposition reactions of PMMA and PVC. However, these objectives are beyond the scope of the present work. The proposed method of calculating average kinetic parameters at different heating rates should enable users to define global kinetic parameters to predict thermal decomposition behavior under a wider range of conditions.

\section{Conclusions}

This paper presents a simple and direct method for calculating the kinetic parameters of polymer thermal decomposition using the Arrhenius equation and a reaction-order model to define the kinetic process. The method achieves a satisfactory balance between accuracy and complexity. The protocol involves selection of three regions in the course of a thermogravimetric experiment to determine the activation energy and pre-exponential factor. The method is applied to the thermogravimetric analysis of several polymers to study the influence of heating rate and polymer decomposition characteristics.

The proposed method is valid for calculating the kinetic parameters of polymer thermal decomposition at different heating rates. The proposed method is superior to the Lyon and GDM methods in terms of fitting the mass- $T$ and $d m / d T-T$ curves of PA 6.6 decomposition at heating rates of $2.5,5,10$, and $40 \mathrm{~K} \mathrm{~min}^{-1}$. The Lyon method is better at providing a heating rate of $20 \mathrm{~K} \mathrm{~min}^{-1}$.

The method is also applicable to distinct patterns of thermal decomposition and to competitive and consecutive reactions. The method is validated by studies of six different polymers at a heating rate of $10 \mathrm{~K} \mathrm{~min}^{-1}$, which demonstrate its applicability to different patterns of behavior including competitive reactions.

In summary, the proposed method provides a more accurate calculation of kinetic parameters and a better description of experimental responses in polymer thermal decomposition.

Author Contributions: Conceptualization, D.L.; methodology, D.L. and M.L.; validation, D.L. and A.A.; formal analysis, D.L. and M.L.; investigation, D.L.; data curation, D.L. and A.A.; writingoriginal draft preparation, D.L.; writing-review and editing, M.L. and D.A.; visualization, D.L.; supervision, D.A.; funding acquisition, D.A. All authors have read and agreed to the published version of the manuscript.

Funding: This research received no external funding.

Institutional Review Board Statement: Not applicable.

Informed Consent Statement: Not applicable.

Data Availability Statement: Data are available on request.

Acknowledgments: Authors would like to thank to the Consejo de Seguridad Nuclear for the cooperation and co-financing the project "Metodologías avanzadas de análisis y simulación de escenarios de incendios en centrales nucleares" and to CAFESTO Project funded by the Spanish Ministry of Science, Innovation and Universities and the Spanish State Research Agency through public-private partnerships (Retos Colaboración 2017 call, ref RTC-2017-6066-8) co-funded by ERDF under the objective "Strengthening research, technological development and innovation".

Conflicts of Interest: The authors declare no conflict of interest. The funders had no role in the design of the study; in the collection, analyses, or interpretation of data; in the writing of the manuscript, or in the decision to publish the results. 


\section{References}

1. McGrattan, K.; Hostikka, S.; Floyd, J.; McDermott, R.; Vanella, M.K. Fire Dynamics Simulator User's Guide. NIST Special Publication 1019, 6th ed.; NIST, VTT: Gaithersburg, MD, USA, 2021.

2. Witkowski, A.; Stec, A.A.; Hull, T.R. Thermal Decomposition of Polymeric Materials. In SFPE Handbook of Fire Protection Engineering, 5th ed.; Springer: New York, NY, USA, 2016; Chapter 7; pp. 1-3493.

3. Vyazovkin, S.; Chrissafis, K.; Di Lorenzo, M.L.; Koga, N.; Pijolat, M.; Roduit, B.; Sbirrazzuoli, N.; Suñol, J.J. ICTAC Kinetics Committee recommendations for collecting experimental thermal analysis data for kinetic computations. Thermochim. Acta 2014, 590, 1-23. [CrossRef]

4. Fedunik-Hofman, L.; Bayon, A.; Donne, S.W.; Hofman, F. Comparative Kinetic Analysis of CaCO3/CaO Reaction System for Energy Storage and Carbon Capture. Appl. Sci. 2019, 9, 4601. [CrossRef]

5. Mahmood, H.; Shakeel, A.; Abdullah, A.; Khan, M.; Moniruzzaman, M. A Comparative Study on Suitability of Model-Free and Model-Fitting Kinetic Methods to Non-Isothermal Degradation of Lignocellulosic Materials. Polymers 2021, 13, 2504. [CrossRef] [PubMed]

6. Blanco, I.; Bottino, F. Kinetics of degradation and thermal behaviour of branched hepta phenyl POSS/PS nanocomposites. Polym. Degrad. Stab. 2016, 129, 374-379. [CrossRef]

7. Vyazovkin, S.; Burnham, A.K.; Criado, J.M.; Perez-Maqueda, L.A.; Popescu, C.; Sbirrazzuoli, N. ICTAC Kinetics Committee recommendations for performing kinetic computations on thermal analysis data. Thermochim. Acta 2011, 520, 1-19. [CrossRef]

8. Šimon, P. Single-step kinetics approximation employing non-Arrhenius temperature functions. J. Therm. Anal. Calorim. 2005, 79, 703-708. [CrossRef]

9. Rogaume, T. Thermal decomposition and pyrolysis of solid fuels: Objectives, challenges and modelling. Fire Saf. J. 2019, 106, 177-188. [CrossRef]

10. Šimon, P. Isoconversional methods: Fundamentals, meaning and application. J. Therm. Anal. Calorim. 2004, 76, 123-132. [CrossRef]

11. Nyazika, T.; Jimenez, M.; Samyn, F.; Bourbigot, S. Pyrolysis modeling, sensitivity analysis, and optimization techniques for combustible materials: A review. J. Fire Sci. 2019, 37, 377-433. [CrossRef]

12. Sharp, J.H.; Wentworth, S.A. Kinetic analysis of thermogravimetric data. Anal. Chem. 1969, 41, 14. [CrossRef]

13. Freeman, E.S.; Carroll, B. The application of thermoanalytical techniques to reaction kinetics. The thermogravimetric evaluation of the kinetics of the decomposition of calcium oxalate monohydrate. J. Phys. Chem. 1958, 62, 394-397. [CrossRef]

14. Coats, A.W.; Redfern, J.P. Kinetic Parameters from Thermogravimetric Data. Nature 1964, 201, 68-69. [CrossRef]

15. Lázaro, D.; Lazaro, M.; Alonso, A.; Lázaro, P.; Alvear, D. Influence of the STA boundary conditions on thermal decomposition of thermoplastic polymers. J. Therm. Anal. Calorim. 2019, 138, 2457-2468. [CrossRef]

16. Vyazovkin, S. Computational aspects of kinetic analysis: Part C. The ICTAC Kinetics Project-The light at the end of the tunnel? Thermochim. Acta 2000, 355, 155-163. [CrossRef]

17. Flynn, J.H.; Wall, L.A. A quick, direct method for the determination of activation energy from thermogravimetric data. J. Polym. Sci. Part B Polym. Lett. 1966, 4, 323-328. [CrossRef]

18. Friedman, H.L. Kinetics of thermal degradation of char-forming plastics from thermogravimetry. Application to a phenolic plastic. J. Polym. Sci. Part C Polym. Symp. 1964, 6, 183-195. [CrossRef]

19. Vyazovkin, S. Modification of the integral isoconversional method to account for variation in the activation energy. J. Comput. Chem. 2001, 22, 178-183. [CrossRef]

20. Akahira, T.; Sunose, T. Method of determining activation deterioration constant of electrical insulating materials. Res. Rep. Chiba Inst. Technol. (Sci. Technol.) 1971, 16, 22-23.

21. Šimon, P.; Thomas, P.; Dubaj, T.; Cibulková, Z.; Peller, A.; Veverka, M. The mathematical incorrectness of the integral isoconversional methods in case of variable activation energy and the consequences. J. Therm. Anal. Calorim. 2013, 115, 853-859. [CrossRef]

22. Matala, A.; Lautenberger, C.; Hostikka, S. Generalized direct method for pyrolysis kinetic parameter estimation and comparison to existing methods. J. Fire Sci. 2012, 30, 339-356. [CrossRef]

23. Friedman, H.L. New methods for evaluating kinetic parameters from thermal analysis data. Polym. Lett. 1969, 7, 41-46. [CrossRef]

24. Mcgrattan, K.; Mcdermott, R.; Mell, W.; Forney, G. Modeling the burning of complicated objects using lagrangian particles. In Proceedings of the 2010 Interflam Conference, Nottingham, UK, 4-7 July 2010; pp. 1-12.

25. Lyon, R.; Safronava, N.; Öztekin, E. A Simple Method for Determining Kinetic Parameters for Materials in Fire Models. In Proceedings of the Fire Safety Science Proceedings of the 10th International Symposium, College Park, MD, USA, 19-24 June 2011; pp. 765-777.

26. Kissinger, H.E. Reaction Kinetics in Differential Thermal Analysis. Anal. Chem. 1957, 29, 1702-1706. [CrossRef]

27. Capote, J.; Alvear, D.; Abreu, O.; Lazaro, M.; Puente, E. Pyrolysis Characterization of a Lineal Low Density Polyethylene. In Proceedings of the Fire Safety Science Proceedings of the 10th International Symposium, College Park, MD, USA, 19-24 June 2011; pp. 877-888.

28. Lautenberger, C.; Rein, G.; Fernandez-Pello, C. The application of a genetic algorithm to estimate material properties for fire modeling from bench-scale fire test data. Fire Saf. J. 2006, 41, 204-214. [CrossRef] 
29. Rein, G.; Lautenberger, C.; Fernandezpello, A.; Torero, J.; Urban, D. Application of genetic algorithms and thermogravimetry to determine the kinetics of polyurethane foam in smoldering combustion. Combust. Flame 2006, 146, 95-108. [CrossRef]

30. Matala, A.; Hostikka, S.; Mangs, J. Estimation of pyrolysis model parameters for solid materials using thermogravimetric data. In Proceedings of the Fire Safety Science Proceedings of the 9th International Symposium, Karlsruhe, Germany, 21-26 September 2008; pp. 1213-1223.

31. Alonso, A.; Lázaro, M.; Lázaro, P.; Lázaro, D.; Alvear, D. LLDPE kinetic properties estimation combining thermogravimetry and differential scanning calorimetry as optimization targets. J. Therm. Anal. Calorim. 2019, 138, 2703-2713. [CrossRef]

32. Purnomo, D.M.; Richter, F.; Bonner, M.; Vaidyanathan, R.; Rein, G. Role of optimisation method on kinetic inverse modelling of biomass pyrolysis at the microscale. Fuel 2019, 262, 116251. [CrossRef]

33. Richter, F.; Rein, G. Pyrolysis kinetics and multi-objective inverse modelling of cellulose at the microscale. Fire Saf. J. 2017, 91, 191-199. [CrossRef]

34. Zanoni, M.A.; Rein, G.; Yermán, L.; Gerhard, J.I. Thermal and oxidative decomposition of bitumen at the Microscale: Kinetic inverse modelling. Fuel 2019, 264, 116704. [CrossRef]

35. Alonso, A.A.; Lázaro, M.; Lázaro, D.; Portilla, A. Thermal oxidative decomposition estimation combining TGA and DSC as optimization targets for PMMA. J. Phys. Conf. Ser. 2018, 1107, 3. [CrossRef]

36. McKinnon, M.B.; Martin, G.E.; Stoliarov, S.I. Pyrolysis model for multiple compositions of a glass reinforced unsaturated polyester composite. J. Appl. Polym. Sci. 2020, 137, 47697. [CrossRef]

37. Matala, A. Methods and Applications of Pyrolysis Modelling for Polymeric Materials. Ph.D. Thesis, VTT Technical Research Centre of Finland, Espoo, Finland, 2013.

38. Lyon, R.E.; Safronava, N. A comparison of direct methods to determine n-th order kinetic parameters of solid thermal decomposition for use in fire models. J. Therm. Anal. Calorim. 2013, 114, 213-227. [CrossRef]

39. ISO 11358-1 Plastics-Thermogravimetry (TG) of Polymers_Part 1: General Principles; European Committee for Standardization: Brussels, Belgium, 2014. 